Check for updates

Westmead Hospital, Westmead NSW, Australia

2 Faculty of Medicine, University of New South Wales, Randwick, NSW, Australia

3 Concord Repatriation General Hospital, Concord, NSW, Australia

4 Faculty of Medicine and Health, University of Sydney, Camperdown, NSW, Australia

Correspondence to: A W Kam andrewkam@ranzco.edu

Cite this as: BMJ2021;372:n109 http://dx.doi.org/10.1136/bmj.n109 Published: 19 January 2021

\section{Protecting the environment from plastic PPE}

\author{
Greener manufacture, use, and disposal are urgent priorities
}

Elissa J Zhang, ${ }^{1,2}$ Lucy P Aitchison, ${ }^{2}$ Nicole Phillips, ${ }^{3,4}$ Ramon Z Shaban, ${ }^{1,4}$ Andrew W Kam ${ }^{1,4}$

Although measures to control covid-19 have been associated with some positive environmental effects, including decreases in global emissions of carbon dioxide, ${ }^{1}$ the pandemic has exacerbated plastic pollution through high use of personal protective equipment (PPE). Single use items include surgical masks, gloves, and non-reusable gowns.

In England alone, 2.3 billion items of single use PPE were distributed to health and social care services between February and July 2020, the same amount distributed throughout the whole of 2019. ${ }^{2}$ Globally, 129 billion face masks and 65 billion gloves are estimated to have been used every month during the covid-19 pandemic. ${ }^{3}$ The disposable face mask market was estimated to have increased from \$80om in 2019 to $\$ 166 \mathrm{bn}$ in 2020.4 If usual patterns of disposal continue, around $75 \%$ of plastic PPE waste related to covid-19 will end up in landfills or ocean environments. ${ }^{4}$ Evidence of improper disposal of PPE is emerging, with plastic masks and gloves found on beaches, ocean beds, and urban environments globally. ${ }^{5} 6$

Surgical face masks, gloves, and gowns are commonly manufactured from plastics that break down slowly, such as polypropylene, polyurethane, polyacrylonitrile, polyethylene, and polyethylene terephthalate. ${ }^{35}$ A surgical mask made from these materials could take 450 years to fully decompose..$^{56}$ These plastics are dispersed globally by wind and ocean currents and may persist as microplastics (fragments $<5 \mathrm{~mm}$ )..$^{-7}$ Plastic pollution has substantial adverse environmental effects, including injury to wildlife (through ingestion) and toxicity to ecosystems (through release of additives or adsorbed contaminants and pathogens). ${ }^{358}$ Growing evidence suggests that microplastics are potentially harmful to aquatic organisms, and enter human food chains, where they may adversely affect health. 59

\section{Better management}

PPE waste overwhelmed waste management systems during the first wave of the pandemic. ${ }^{10}{ }^{11}$ Capacity for local incineration, the mainstay of clinical waste disposal, was exceeded, increasing use of landfill and potentially contributing to improper PPE disposal. ${ }^{1011}$ In Wuhan, China, clinical waste increased fourfold during its covid-19 outbreak, and mobile incinerators were deployed to meet demand. ${ }^{10}$ In the UK, municipal waste incinerators were given permission to process medical waste. ${ }^{10}$ Although incinerators have adverse environmental consequences, including greenhouse gas emissions and release of hazardous compounds such as dioxins, their overall harm is less than landfill if appropriate pollution controls and technologies are used. ${ }^{811} 12$ Capacity strains on waste management systems have highlighted the need to consider surge capacity and the environmental impact of waste in disaster management plans. ${ }^{13}$

Another challenge to waste management is that contaminated PPE could transmit disease. ${ }^{14}$ This potential risk, combined with the complex composition of some types of single use PPE, make waste recycling challenging. Surgical masks, for example, contain multiple different plastic polymers and other materials. Waste from masks must be separated into component parts and sterilised before processing. ${ }^{811}$ Research into better methods of recycling PPE is ongoing, exploring methods such as feedstock recycling-breaking polymers into smaller molecules that can be used to create new products-or conversion into liquid fuels. ${ }^{11} 1315$

Single use PPE is vital to prevent infection and control disease in healthcare settings, alongside other measures such as physical distancing, hand hygiene, and source isolation. ${ }^{16}$ Although vaccines are expected to reduce the spread of covid-19, roll-out across the global population faces multiple logistic challenges and is likely to be slow. ${ }^{17}$ The increased use of disposable PPE is likely to persist. Strategies to reduce unnecessary exposure to potential pathogens, such as physical distancing and source isolation, should be the first line of defence, before PPE is needed, to reduce infection risk in healthcare settings and among the public. ${ }^{18}$ Rational and evidence based use of PPE will help reduce risk of shortages and control unnecessary waste. ${ }^{18}$

Aside from PPE related waste, the pandemic has increased consumption of single-use plastic more broadly. ${ }^{38}$ This has been driven by what is likely to be a permanent shift towards industries that require more single use plastics (eg, e-commerce and takeaway food providers) and a public perception that single use plastics are more hygienic. Governments in the UK, Portugal, and some US states have reversed or delayed environmental policies restricting single use plastics during the pandemic. ${ }^{3111319}$ Although justified by the public health crisis, these policy changes have slowed hard won progress towards reducing the global impact of plastic pollution. ${ }^{1113}$ It is now even more important that governments and non-governmental organisations design and implement policies to reduce use of plastics; develop alternative materials; promote a circular plastic economy where plastic products are recycled, refined, or reused at the end of their lifecycle; and educate the public. Together, these changes would help reduce the grave environmental threat caused by plastic pollution.

The covid-19 pandemic has greatly exacerbated the global environmental threat of plastic pollution. 
Although management of the public health crisis is the priority, governments and healthcare systems must simultaneously implement strategies to mitigate the environmental consequences of the pandemic.

Competing interests: We have read and understood BMJ policy on declaration of interests and declare the following interests: NP, RS, and AK are in the process of seeking intellectual property right protection for a modelling software to assist clinicians and administrators for planning PPE demand across healthcare systems. The software is under development in partnership with the University of Sydney and the Western Sydney Local Health District. The software is not commercially active and we do not have any financial gain from this software.

Provenance and peer review: Not commissioned; externally peer reviewed.

1 Le Quéré C, Jackson RB, Jones MW, etal. Temporary reduction in daily global CO2 emissions during the COVID-19 forced confinement. Nat Clim Chang 2020;10:647-53doi: 10.1038/s41558-020-0797-x

2 Way C. Healthcare is still hooked on single-use plastic PPE, but there are more sustainable options. The Conversation2020. https://theconversation.com/healthcare-is-still-hooked-on-singleuse-plastic-ppe-but-there-are-more-sustainable-options-143940

3 Prata JC, Silva ALP, Walker TR, Duarte AC, Rocha-Santos T. COVID-19 pandemic repercussions on the use and management of plastics. Environ Sci Technol 2020;54:7760-5. doi: 10.1021/acs.est.0c02178 pmid: 32531154

4 United Nations Conference on Trade and Development. Growing plastic pollution in wake of COVID-19: how trade policy can help. 27 Jul 2020. https://unctad.org/en/pages/newsdetails.aspx?OriginalVersion $I D=2440$

5 Fadare 00, Okoffo ED. Covid-19 face masks: a potential source of microplastic fibers in the environment. Sci Total Environ 2020;737:140279.

doi: 10.1016/j.scitotenv.2020.140279 pmid: 32563114

6 Kassam A. "More masks than jellyfish": coronavirus waste ends up in ocean. 2020. Guardian 2020 Jun 8. https://www.theguardian.com/environment/2020/jun/08/more-masks-than-jellyfishcoronavirus-waste-ends-up-in-ocean

7 Ajith N, Arumugam S, Parthasarathy S, Manupoori S, Janakiraman S. Global distribution of microplastics and its impact on marine environment-a review. Environ Sci Pollut Res Int 2020;27:25970-86. doi: 10.1007/s11356-020-09015-5 pmid: 32382901

8 Patrício Silva AL, Prata JC, Walker TR, etal. Increased plastic pollution due to covid-19 pandemic: challenges and recommendations. Chem Eng /2021;405:126683. doi: 10.1016/j.cej.2020.126683 pmid: 32834764

9 Ragusa A, Svelato A, Santacroce C, etal. Plasticenta: first evidence of microplastics in human placenta. Environ Int 2021;146:106274. doi: 10.1016/j.envint.2020.106274 pmid: 33395930

10 Fletcher C. What happens to waste PPE during the coronavirus pandemic? The Conversation 2020. https://theconversation.com/what-happens-to-waste-ppe-during-the-coronavirus-pandemic-137632

11 Vanapalli KR, Sharma HB, Ranjan VP, etal. Challenges and strategies for effective plastic waste management during and post COVID-19 pandemic. Sci Total Environ 2021;750:141514. doi: 10.1016/j.scitotenv.2020.141514 pmid: 32835961

12 Kumar H, Azad A, Gupta A, etal. Covid-19 creating another problem? Sustainable solution for PPE disposal through LCA approach. Environ Dev Sustain 2020:1-15.pmid: 33071605

13 Sharma HB, Vanapalli KR, Cheela VS, etal. Challenges, opportunities, and innovations for effective solid waste management during and post COVID-19 pandemic. Resour Conserv Recycl 2020;162:105052. doi: 10.1016/j.resconrec.2020.105052 pmid: 32834486

14 van Doremalen N, Bushmaker T, Morris DH, etal. Aerosol and surface stability of SARS-CoV-2 as compared with SARS-CoV-1. N Engl J Med 2020;382:1564-7. doi: 10.1056/NEJMc2004973 pmid: 32182409

15 Jain S, Yadav Lamba B, Kumar S, etal. Strategy for repurposing of disposed PPE kits by production of biofuel: pressing priority amidst COVID-19 pandemic. Biofuels 2020:1-5. doi: 10.1080/17597269.2020.1797350

16 Chu DK, AkI EA, Duda S, Solo K, Yaacoub S, Schünemann HJCOVID-19 Systematic Urgent Review Group Effort (SURGE) study authors. Physical distancing, face masks, and eye protection to prevent person-to-person transmission of SARS-CoV-2 and COVID-19: a systematic review and meta-analysis. Lancet2020;395:1973-87. doi: 10.1016/S0140-6736(20)31142-9 pmid: 32497510

17 Van Gogh M, Hausmann L, Wolff C, et al. Is the world up to the challenge of mass COVID-19 vaccination? World Economic Forum, 2020. https://www.weforum.org/agenda/2020/12/is-theworld-up-to-the-challenge-of-mass-covid-19-vaccination/

18 World Health Organization. Rational use of personal protective equipment (PPE) for coronavirus disease (COVID-19) and considerations during severe shortages: interim guidance. 2020. https://www.who.int/publications/i/item/rational-use-of-personal-protective-equipment-forcoronavirus-disease-(covid-19)-and-considerations-during-severe-shortages

19 Patrício Silva AL, Prata JC, Walker TR, etal. Rethinking and optimising plastic waste management under COVID-19 pandemic: policy solutions based on redesign and reduction of single-use plastics and personal protective equipment. Sci Total Environ 2020;742:140565.

doi: 10.1016/j.scitotenv.2020.140565 pmid: 32622168 